Artigos

Volume 8 - 2018|n. 8

\title{
Os reflexos no financiamento do sistema estadual de ensino público da Bahia resultantes da nova política de financiamento da educação básica no Brasil
}

\author{
Jean Mário Araújo Costa \\ Maria Couto Cunha \\ Cláudia Sá Malbouisson Andrade \\ Universidade Federal da Bahia (UFBA), Salvador/BA - Brasil
}

\section{Resumo}

O presente artigo discute as mudanças na política de financiamento da educação básica brasileira pós Constituição Federal de 1988 e seus reflexos no financiamento do sistema estadual de ensino da Bahia, no período de 2009 a 2016. Parte-se dos principais marcos dessa política, tendo como foco os percentuais da receita de impostos aplicados em educação; o montante de recursos aportados e recebidos do Fundo de Manutenção e Desenvolvimento da Educação Básica e Valorização dos Profissionais da Educação; e a projeção de complementação desse Fundo para a garantia do Custo Aluno Qualidade Inicial (CAQi). A metodologia do estudo contemplou a análise documental e o levantamento bibliográfico. Os resultados revelaram efeitos significativos e peculiares no financiamento desse sistema, contudo, não evidenciam os meios para uma política de financiamento sustentável e efetiva, no sentido de superação das desigualdades regionais e o alcance de uma educação pública de qualidade.

Palavras-chave: Políticas Públicas. Financiamento da Educação Básica. Financiamento da Educação Pública no Estado da Bahia.

\section{The reflections on the financing of the Bahia state school system resulting from the new financing policy of $K-12$ education in Brazil}

\section{Abstract}

This article discusses the changes in the financing policy of Brazilian K-12 education following the 1988 Federal Constitution and its impact on the financing of the state education system of Bahia, from 2009 to 2016. It is based on the major milestones of this policy, focusing the percentages of tax revenue invested on education; the amount of resources contributed and received under the Fund for the Maintenance and Development of K-12 Education and Enhancement of Education Professionals; and the projection of complementation of this Fund for the guarantee of the Initial Quality Student Cost (CAQi). The methodology of the study was based on documental analysis and bibliographical survey. The results revealed significant and peculiar effects on the financing of this system, however, they do not show the means for a sustainable and effective financing policy, in order to overcome regional inequalities and the achievement of a quality public education.

Keywords: Public Policies. Funding of K-12 Education. Financing of Public Education in the State of Bahia. 
Os reflexos no financiamento do sistema estadual de ensino público da Bahia resultantes da nova política de financiamento da educação básica no Brasil

\section{Introdução}

Os valores que orientam a formulação das políticas públicas acompanham os princípios estabelecidos em cada momento histórico. Diante desse movimento, a educação é tida nos tempos atuais como um dos maiores recursos de que dispõem os governos para enfrentar os desafios dos novos cenários do ponto de vista social, político e econômico. Assim, a educação escolar, objeto de políticas públicas, cumpre destacado papel nos processos formativos por meio dos diferentes níveis, ciclos e modalidades educativas.

Nessa perspectiva, a educação pode ser vista como valioso instrumento capaz de promover, conjuntamente, o desenvolvimento econômico e o desenvolvimento social de um país. Além disso, Cury (2002) destaca que a educação como direito e sua efetivação em práticas sociais convertem-se em instrumento de redução das desigualdades e das discriminações e possibilitam uma aproximação pacífica entre os povos de todo o mundo.

A política de financiamento da educação apresenta-se como tema central quando se discute não somente $\mathrm{o}$ desenvolvimento no aspecto educacional, mas também 0 desenvolvimento nacional. A realização de pesquisas sobre financiamento da educação tem despertado grande interesse entre os educadores e tem tido espaço significativo na área da pesquisa em Educação. Para Martins (2010), o financiamento é um componente muito importante da política setorial da educação, um instrumento de sua realização que merece um espaço próprio de investigação. Para esse autor (2010, p. 499), há "[...] uma ambiguidade ou hibridismo das políticas públicas de financiamento da educação: são determinadas pelas políticas educacionais ao mesmo tempo em que são determinantes". De fato, a insuficiência de recursos financeiros para o desenvolvimento de políticas importantes para o setor da educação, no Brasil, tem levado a que grande parte da demanda educacional não seja atendida.

Nessa linha de argumentação, o nosso país configurou uma educação que durante anos postergou enfrentamentos necessários, como o baixo atendimento em creches e pré-escolas, a universalização do ensino médio e maior cobertura do ensino superior. Portanto, o desafio para a construção de uma educação como vetor de desenvolvimento e de redução das desigualdades perpassa, sobretudo, pelo financiamento.

A Lei de Diretrizes e Bases da Educação Nacional n. 9.394/96 (LDBEN/96), em seu art. $4^{\circ}$, inciso IX, estabelece o dever do Estado com a educação escolar pública através da garantia de padrões mínimos de qualidade de ensino, definidos como a variedade e a quantidade mínimas, por aluno, de insumos indispensáveis ao desenvolvimento do processo de ensino-aprendizagem. Nesse sentido, a legislação brasileira já determina o cumprimento da oferta da educação, com qualidade, o que demanda volume adequado de recursos financeiros.

Este artigo tem o objetivo de apresentar um panorama geral sobre as mudanças da política de financiamento da educação básica brasileira pós Constituição Federal de 1988 (CF/88) e seus reflexos no financiamento do sistema estadual de ensino da Bahia, no período de 2009 a 2016. Parte-se dos principais marcos da política de financiamento da educação básica, no Brasil, para se discutir, no âmbito do governo do Estado da Bahia, os percentuais da receita de impostos aplicados em educação, o montante de recursos aportados e recebidos do Fundo de Manutenção e Desenvolvimento da Educação Básica e Valorização dos 
Os reflexos no financiamento do sistema estadual de ensino público da Bahia resultantes da nova política de financiamento da educação básica no Brasil

Profissionais da Educação (Fundeb) e a projeção de complementação desse Fundo para a garantia do padrão mínimo de qualidade via Custo Aluno Qualidade Inicial (CAQi).

A metodologia para realização do estudo contemplou a análise documental e o levantamento bibliográfico. O período do estudo, de 2009 a 2016, justifica-se devido ao Relatório que deu origem a este trabalho, com dados posteriormente atualizados. O Relatório teve a finalidade de contribuir com as discussões iniciais no âmbito do Fórum Estadual de Educação da Bahia (FEE-BA), para o processo de monitoramento e avaliação do Plano Estadual de Educação, aprovado pela Lei n. 13.559, de 11 de maio de 2016. Considera-se relevante discutir sobre esses assuntos, dada a pouca densidade de estudos nesse campo.

\section{As (in)definições do financiamento da educação básica no Brasil}

A história do financiamento da educação básica pública do País é permeada de avanços e retrocessos, a depender das configurações políticas de cada momento. Nos períodos de centralismo político, diminuem os dispositivos legais que possam garantir os recursos. Noutros momentos em que o País experimenta regimes mais democráticos, essas garantias se apresentam na legislação. Essa análise tem mostrado, portanto, um contexto de (in)definições em vários períodos históricos, apresentando elementos capazes de contribuir para um melhor entendimento da sua atual configuração. Tendo em vista o objetivo deste trabalho, optou-se em apresentar, inicialmente, uma síntese dos elementos constitutivos deste cenário, a partir da visão de alguns autores.

Vieira e Vidal (2015) destacam que a trajetória do financiamento da educação é marcada por três principais momentos na história brasileira, guardando uma sintonia com o contexto político mais geral. A sucessão desses momentos mantém a característica de incertezas quanto às formas de garantir recursos para a educação. Um primeiro momento se caracteriza pela indefinição de recursos, que começa com a chegada dos jesuítas, no Brasil, até as três primeiras décadas do século $\mathrm{XX}$, quando os agentes e fontes de recursos não são claramente identificados. O segundo momento, a que as autoras chamaram de segunda geração, representa a fase em que é determinada a vinculação de recursos nas constituições brasileiras, iniciada com a Carta Magna de 1934, demonstrando uma preocupação em garantir recursos advindos de impostos que os entes federados deveriam aplicar em educação. Nesse momento, registram-se avanços e recuos na legislação que se seguiu, com alternância de dispositivos sobre esse assunto nas constituições até chegar à Constituição de 1988, quando a vinculação de recursos para a educação é retomada. O terceiro momento começa na década de 90 do século $X X$, quando é criado um fundo específico para o financiamento do ensino fundamental - o Fundo de Manutenção e Desenvolvimento do Ensino Fundamental e Valorização do Magistério (Fundef) -, para que fossem garantidos recursos para o ensino obrigatório, como marco inicial da geração das políticas de fundos.

Do mesmo modo, os autores Gouveia e Souza (2015), fazendo uma retrospectiva sobre as políticas de financiamento no Brasil, identificam quatro momentos dessa história, caracterizada por mudanças nas formas de reservar recursos para a educação. Um primeiro período, que corresponde à ausência do Estado nesse financiamento, entre os anos de 1549 e 1750, quando os jesuítas foram expulsos do Brasil; um segundo, em que se buscou fontes autônomas de financiamento, ainda que de formas frágeis, como o subsídio literário; um terceiro período, que imperou a partir de 1934, com a primeira Constituição brasileira, até o final do século $X X$, quando os dispositivos sobre a vinculação de recursos para a educação 
Os reflexos no financiamento do sistema estadual de ensino público da Bahia resultantes da nova política de financiamento da educação básica no Brasil

se alternavam nas constituições que se seguiram. Esses autores propuseram considerar um quarto período para analisar a trajetória do financiamento da educação brasileira, identificando a fase da política de fundos, que corresponde ao terceiro momento, assinalado por Vieira e Vidal (2015).

Como se pode observar, as definições sobre o financiamento da educação brasileira sofrem de um movimento de avanços, rupturas e de incertezas, que tem comprometido o desenvolvimento das políticas que poderiam levar à superação dos problemas de atendimento à demanda e à garantia dos direitos à educação, consagrados em sucessivas constituições do País. Detém-se, a seguir, sobre as mudanças efetuadas nesse ordenamento jurídico, a partir da Constituição Federal de 1988.

\section{As principais mudanças na política de financiamento da educação básica brasileira pós CF/88}

A CF/88 estabeleceu o modelo de federalismo cooperativo a ser sedimentado por meio do regime de colaboração recíproca, descentralizado, com funções compartilhadas entre entes federativos. Desse modo, a organização do sistema educacional brasileiro, segundo a Constituição, caracteriza-se pela divisão de competências e responsabilidades entre a União, Distrito Federal, os estados e municípios, o que se aplica também ao financiamento e à manutenção dos diferentes níveis, etapas e modalidades da educação e do ensino.

Além de estabelecer a organização dos sistemas de ensino, via regime de colaboração entre os entes federados (art. 211), a CF/88 (art. 212) vincula um percentual mínimo da receita resultante de impostos que cada ente deve aplicar na manutenção e desenvolvimento do ensino (MDE), sendo a União 18\%, e estados, Distrito Federal e municípios, 25\%, para que a oferta da educação básica seja garantida.

Na década de 1990, diante de um diagnóstico da grave desigualdade na arrecadação de recursos próprios pelos estados e municípios, com valores anuais por aluno em educação bastante assimétricos, e como resposta às pressões dos organismos internacionais por melhoria nos indicadores educacionais no ensino fundamental, houve expressiva modificação na estrutura e na dinâmica do financiamento da educação brasileira com a implantação da política de fundos. Dessa forma, o Governo Federal optou por focalizar os recursos nessa etapa da educação básica, instituindo, através da Emenda Constitucional (EC) n. 14/1996, o Fundef, que subvinculou $15 \%$ da receita dos seguintes impostos e transferências ao ensino fundamental: FPM, FPE, ICMS, IPI-Exportação e LC 87/96².

Em 2006, por meio da EC n. 53/2006, foi instituído, em substituição ao Fundef, o Fundeb, para o período de 2007 a 2020. Juntamente com os impostos e transferências que já integravam o Fundef, foram incorporados como base de incidência do fundo outros três impostos: IPVA, ITCMD e ITR², sendo que o percentual da vinculação de cada imposto passou para $20 \%$ dos recursos arrecadados. Para efeito de repasse do Fundeb, foram contabilizadas

1 Fundo de Participação dos Municípios, Fundo de Participação dos Estados, Imposto de Circulação de Mercadorias e Serviços, Imposto sobre Produtos Industrializados proporcional às Exportações e desoneração das exportações prevista na Lei Complementar n 87/96 (Lei Kandir).

2 Imposto sobre a Propriedade de Veículos Automotores, Imposto sobre Transmissão Causa Mortis e Doação e Imposto sobre a Propriedade Territorial Rural. 
Os reflexos no financiamento do sistema estadual de ensino público da Bahia resultantes da nova política de financiamento da educação básica no Brasil

as matrículas no ensino fundamental e no ensino médio para os estados, e na educação infantil e no ensino fundamental para os municípios.

Além desses recursos, fez parte das receitas do Fundef, e atualmente compõe o Fundeb, uma parcela de recursos federais, a título de complementação, sempre que, no âmbito de cada estado, seu valor por aluno não alcançar o mínimo definido nacionalmente.

Com a política de fundos na educação, houve significativa queda nos diferenciais de financiamento educacional intraestaduais, pois o valor aluno/ano repassado pelos fundos é único dentro de cada fundo estadual, independentemente da capacidade contributiva de cada esfera de governo.

Outro fato que modificou a estrutura da educação básica brasileira e seu financiamento em 2009 foi a promulgação da EC n. 59. Além de ampliar o ensino obrigatório de 6 a 14 anos, para 4 a 17 anos de idade, essa emenda determinou o fim gradativo da desvinculação das receitas da União (DRU), adotada em 1994, quando da implementação do Plano Real, com o objetivo de aumentar a flexibilidade para que o governo federal usasse os recursos do orçamento nas finalidades que considerasse necessárias. Logo, essa emenda amplia o contingente de alunos que passam a ter o ensino obrigatório, o que vai demandar mais recursos para a educação. Por outro lado, o fim da DRU fez disponibilizar maior aporte de recursos, salvaguardando melhor as receitas que eram reservadas à manutenção de desenvolvimento do ensino. Foram mudanças que provocaram impactos no financiamento da educação.

Em 2010, através do Parecer n. 8/2010, o Conselho Nacional de Educação/Câmara de Educação Básica estabeleceu normas para aplicação do inciso IX do artigo $4^{\circ}$ da LDBEN/96, que trata dos padrões mínimos de qualidade de ensino para a educação básica pública. É nesse parecer que o indicador Custo Aluno Qualidade Inicial (CAQi) é reconhecido pela primeira vez como garantia para que cada cidadão do País tenha acesso a uma educação de qualidade.

O CAQi é entendido como um primeiro passo rumo à educação pública de qualidade no Brasil, ou seja, ponto de partida relativamente aos insumos básicos que todas as escolas deveriam assegurar, tendo como expectativa o alcance do CAQ (Custo Aluno Qualidade), definido como "custo potencial de um aluno de educação básica durante o período de um ano, recebendo um ensino de qualidade" (JESUS, 2012, p. 220). A origem do CAQi e do CAQ remete a um amplo debate sobre a qualidade e financiamento da educação no âmbito da Campanha Nacional pelo Direito à Educação, tendo como referência, principalmente, os estudos do pesquisador José Marcelino Rezende Pinto.

A composição do CAQi contempla os insumos básicos que todas as escolas deveriam assegurar. Dessa forma, traduz-se em um indicador que mostra quanto deve ser investido ao ano por aluno em cada etapa e modalidade da educação básica. A sua institucionalização justifica-se pelo seu efeito equalizador, já que, com sua implantação, valores equivalentes deverão ser disponibilizados a todas as unidades da federação.

Destaca-se no Parecer n. 8/2010, acima referido, a fixação do prazo de adoção do CAQi, até 2016, como política pública pelos sistemas de ensino da União, dos estados, Distrito Federal e municípios, os quais deveriam estabelecer diretrizes e metas, mediante planos de ação orgânicos e articulados em regime de colaboração, como instrumentos de melhoria e modernização da gestão educacional (art. 17). Apesar disso, até a elaboração deste artigo, o 
Os reflexos no financiamento do sistema estadual de ensino público da Bahia resultantes da nova política de financiamento da educação básica no Brasil

referido parecer não havia sido homologado pelo Ministério da Educação, esgotando, assim, as possibilidades de atendimento ao prazo estipulado, comprometendo, consequentemente, os futuros desdobramentos político-administrativos para se chegar ao CAQ. Portanto, os reflexos dessa proposição, no financiamento da educação básica brasileira, ainda não se registram na sua efetividade.

Ainda como parte das mudanças legais ocorridas no financiamento da educação básica brasileira, pode-se indicar a Lei n. 12.858, de 9 de setembro de 2013, que dispõe sobre a aplicação de $75 \%$ dos royalties de petróleo e $50 \%$ do excedente em óleo do pré-sal na educação. Contudo, as previsões de recursos significativos para a educação são pouco seguras, pois dependem de inúmeros fatores, como tamanho das reservas, possibilidade e custos de extração e preço internacional do produto. Ademais, a materialização desse dispositivo está a merecer desdobramentos mais precisos por parte da legislação do País, inclusive diante das alterações das regras de exploração do pré-sal, promovidas na legislação brasileira com a Lei 13.365/16, que estabelece o fim da obrigatoriedade da Petrobrás na exploração do pré-sal. Isso poderá acarretar implicações com relação à previsão de recursos para a educação proveniente dessa fonte.

Importante ressaltar que a EC n. 59/2009, citada anteriormente, alterou o texto do art. 214 da CF/88, estabelecendo que o Plano Nacional de Educação, de duração decenal, deve ter o objetivo de articular o sistema nacional de educação em regime de colaboração e definir diretrizes, objetivos, metas e estratégias de implementação, para assegurar a manutenção e desenvolvimento do ensino em seus diversos níveis, etapas e modalidades. A referida EC tratou, também, do estabelecimento de meta de aplicação de recursos públicos em educação como proporção do produto interno bruto (PIB) (art. 214, Inc. VI).

Em consonância com a EC n. 59/2009, o novo Plano Nacional de Educação, Lei 13.005/2014 (PNE 2014-2024), trouxe, em seu bojo, a meta 20, que trata do financiamento da educação, elemento-chave ao cumprimento de todas as outras metas. Essa meta constituise em um dos principais pilares do plano e trata da ampliação do investimento público em educação pública, de forma a atingir, no mínimo, o patamar de $7 \%$ do PIB do País, no $5^{\circ}$ ano de vigência da Lei e, no mínimo, o equivalente a $10 \%$ do PIB ao final do decênio. Observa-se do escopo da lei que o Custo Aluno Qualidade se firmou como parâmetro para a materialização do "padrão mínimo de qualidade".

Ocorre que, desde a CF/88, tem-se a previsão de "padrão mínimo de qualidade". Oito anos após a sua promulgação, quando da aprovação da LDBEN/96, o tema voltou à cena, sendo um pouco mais detalhado, referindo-se aos "padrões mínimos de qualidade de ensino, definidos como a variedade e a quantidade mínimas, por aluno, de insumos indispensáveis ao desenvolvimento do processo de ensino-aprendizagem" (inciso IX, art. $4^{\circ}$ ), conforme já discutido neste texto. Somente com o PNE 2014-2024 surge a definição do padrão mínimo de qualidade, via definição do patamar de investimento público direto em políticas educacionais como proporção do PIB. Contudo, para garantir a elevação da quantidade de recursos investidos na área, torna-se necessário estabelecer quais as fontes de recursos serão utilizadas e qual o papel de cada esfera de governo, dentro de um regime de colaboração. Esse tem sido um tema latente, que está a requerer melhores esclarecimentos e maior determinação, o que tem suscitado um debate vigoroso entre aqueles que se interessam pela implementação das políticas da educação básica do País, constituindo-se, ainda, em uma questão aberta, no cenário político atual. 
Os reflexos no financiamento do sistema estadual de ensino público da Bahia resultantes da nova política de financiamento da educação básica no Brasil

Toda a política empreendida pelo Estado requer a determinação de um orçamento específico. Desse modo, não é possível realizar uma política educacional, com padrão de qualidade, tendo em vista a redução das desigualdades e ao desenvolvimento econômico e social de um país, sem a destinação adequada de recursos. Consonante a isso, Cara (2012, p. 125-126) destaca que "[...] embora seja errôneo assegurar que o financiamento adequado da educação pública resolva sozinho o complexo conjunto de problemas educacionais brasileiros, é certo afirmar que sem ele nada poderá ser feito".

Diante do que foi discutido, infere-se que o direito à educação, estabelecido no texto constitucional de 1988, como lídimo direito programático, exige condições de implementação através de padrão mínimo de qualidade, o que demanda maiores investimentos públicos para a redefinição das prioridades em atendimento à expansão desse direito.

Não é à toa que, em relação aos direitos dessa natureza, Bobbio (1992) destaca que a gênese histórica de um direito começa como uma exigência social, que vai se afirmando até se converter em direito positivo. Essa conversão ainda não significa a universalização desse direito. O momento da universalização indica que aquela exigência, já posta como direito, se torna generalizada para todos os cidadãos ou amplia os níveis de atendimento. É o que se pretende alcançar com o PNE 2014-2024 e suas variações estaduais e municipais.

\section{Os reflexos do financiamento da educação básica brasileira no financiamento do sistema estadual público de ensino da Bahia (2009 a 2016)}

Diante do que foi exposto, dentre as principais mudanças legais ocorridas na política de financiamento da educação básica brasileira pós CF/88, destacam-se: a vinculação de percentuais mínimos de receitas provenientes de impostos à manutenção e desenvolvimento do ensino (CF/88), a política de fundos materializada através do Fundef e do Fundeb (EC n. 14/96 e EC n. 53/2006, respectivamente) e a definição do padrão mínimo de qualidade, via patamar de investimento público direto em políticas educacionais como proporção do PIB (PNE 2014-2024). Desse modo, tais marcos serão tomados como referência para a discussão sobre o financiamento da educação básica brasileira e seus reflexos no financiamento da educação pública do sistema estadual de ensino da Bahia.

Em se tratando da vinculação de percentuais à educação, a Constituição Federal de 1988 (art. 212) vincula um percentual de recursos específicos, que cada ente é obrigado a empenhar na manutenção e desenvolvimento do ensino. As ações compreendidas nesse âmbito são todas aquelas que visam alcançar os objetivos básicos da educação nacional, ou seja, são aquelas voltadas à obtenção dos objetivos das instituições educacionais de todos os níveis. É importante destacar que a LDBEN/96 estabelece as despesas consideradas como manutenção e desenvolvimento do ensino no seu artigo 70 :

\footnotetext{
I - remuneração e aperfeiçoamento do pessoal docente e demais profissionais da educação;

II - aquisição, manutenção, construção e conservação de instalações e equipamentos necessários ao ensino;

III - uso e manutenção de bens e serviços vinculados ao ensino;

IV - levantamentos estatísticos, estudos e pesquisas visando precipuamente ao aprimoramento da qualidade e à expansão do ensino;
} 
Os reflexos no financiamento do sistema estadual de ensino público da Bahia resultantes da nova política de financiamento da educação básica no Brasil

V - realização de atividades-meio necessárias ao funcionamento dos sistemas de ensino;

$\mathrm{VI}$ - concessão de bolsas de estudo a alunos de escolas públicas e privadas;

VII - amortização e custeio de operações de crédito destinadas a atender ao disposto nos incisos deste artigo;

VIII - aquisição de material didático-escolar e manutenção de programas de transporte escolar.

Com base nos critérios considerados no cômputo com gastos de manutenção e desenvolvimento do ensino, apresentam-se, a seguir, dados gerais sobre os percentuais mínimos da receita resultante de impostos, aplicados pelo governo do Estado da Bahia em educação, no período de 2009 a 2016.

\section{Gráfico 1 - Percentuais da receita resultante de impostos aplicados pelo governo do Estado da Bahia na manutenção e desenvolvimento do ensino - 2009 a 2016 (\%)}

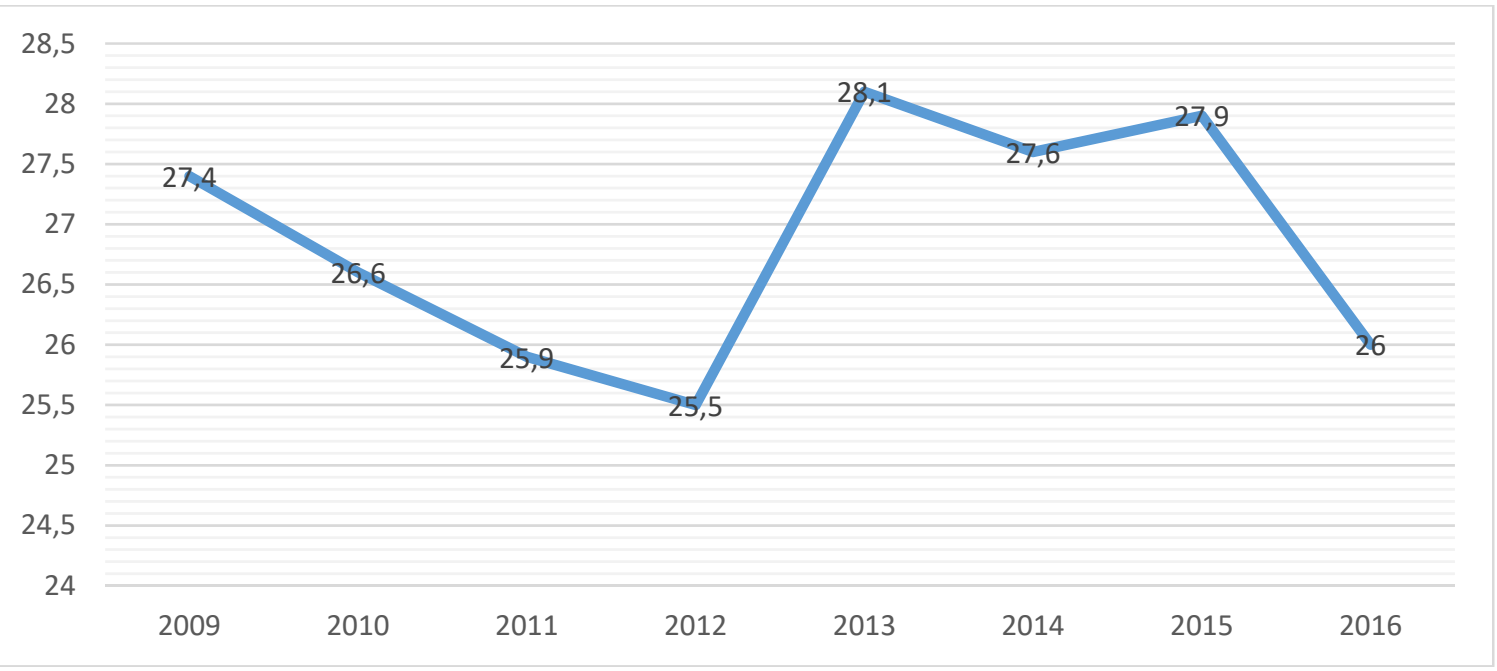

Fonte: BAHIA/TCE $(2010 ; 2011 ; 2012 ; 2013 ; 2014 ; 2015 ; 2016 ; 2017)$

Constata-se que, no período de 2009 a 2012, houve um decréscimo nos percentuais da receita resultante de impostos aplicados em manutenção e desenvolvimento do ensino, correspondente a $27,4 \% ; 26,6 \% ; 25,9 \%$ e 25,5\%, respectivamente. Em 2013, evidencia-se um acréscimo de 2,6\% em relação ao ano de 2012, atingindo o maior percentual da receita de impostos, no período selecionado, ou seja, 28,1\%. Além disso, em 2014 e em 2015 os percentuais permaneceram acima dos $27,5 \%$. Já em 2016 , os mesmos reduziram para $26 \%$, indicando maior queda do período em relação ao ano anterior, ou seja, 1,9\%. Apesar disso, os dados indicam que o governo do Estado da Bahia cumpriu com o limite mínimo constitucional de $25 \%$ da receita resultante de impostos investidos no ensino.

Isso pode revelar um indicador positivo para o atendimento à educação no Estado. No entanto, deve-se considerar, conforme assinalado anteriormente, que houve no último ano um decréscimo significativo nos percentuais da receita resultante de impostos aplicados em manutenção e desenvolvimento do ensino no Estado da Bahia. Além disso, a elevação desses percentuais, a exemplo do ano $2013(28,1 \%)$, não significa, necessariamente, que os recursos aumentaram. Novas pesquisas deverão investigar tal relação. Pesquisa realizada por Silva e Jesus (2016), nos cinco estados do País com maior arrecadação de cada região (São Paulo, Amazonas, Bahia, Goiás e Rio Grande do Sul), constatou que as receitas resultantes do ICMS (o imposto que mais gera receita nos estados), em todos eles, tenderam a diminuir na série de anos 2006/2015. Para esses autores, mesmo que o financiamento, por força de lei seja 
Os reflexos no financiamento do sistema estadual de ensino público da Bahia resultantes da nova política de financiamento da educação básica no Brasil

garantido, ele não resulta, na prática, em resolução do problema de escassez de recursos, uma vez que depende da capacidade arrecadatória dos entes federados. A baixa arrecadação em cada uma das instâncias de governo poderá impactar em outras esferas, deixando-as na dependência dos repasses constitucionais.

Partindo para o segundo marco de mudanças no financiamento da educação básica brasileira, chega-se à política de fundos. Por fundos se entende toda e qualquer medida regulamentadora (leis, decretos e emendas) estabelecida pelo Estado brasileiro com a finalidade de instituir meio específico de financiamento com recursos de diferentes procedências, visando um fim específico (GEMAQUE, 2004). A política de fundos na educação básica brasileira pode ser entendida como um mecanismo orçamentário contábil de redistribuição de recursos e se traduz num conjunto de normas legais derivadas da aprovação da EC n. 14/96 e EC n. 53/2006.

A instituição dessa política implicou alterações profundas na educação brasileira, no que diz respeito à oferta de ensino e também à estrutura orçamentário-financeira das administrações públicas. A discussão inicial sobre os fundos na educação remonta ao período marcado pelo Movimento dos Pioneiros, na década de 1930. Apesar disso, essa política somente foi adotada a partir dos anos de 1990, com a EC n. 14/1996, que instituiu o Fundef com a finalidade de reduzir as disparidades regionais em termos de receitas orçamentárias para a educação.

Em síntese, o Fundef era formado por $15 \%$ dos impostos anteriormente assinalados, arrecadados no País, e por uma complementação federal. Esses recursos deveriam ser empregados exclusivamente na manutenção e desenvolvimento do ensino fundamental, o que provocou impacto negativo no atendimento da educação infantil, ensino médio e na modalidade educação de jovens e adultos. Outro efeito do Fundef constituiu na mudança de responsabilização da oferta das etapas do ensino. Estudos de Pinto (2007) dão conta de que, ao atrelar parcela dos recursos vinculados à educação à matrícula no ensino fundamental regular, o fundo induziu um processo de municipalização sem precedentes no Brasil. Essa constatação foi confirmada no Estado da Bahia através dos estudos de Costa (2008), que revelaram uma adesão acentuada dos municípios baianos ao processo de municipalização promovido pelo governo estadual, a partir de 1998.

As mudanças ocorridas nesse período com o Fundef e as mudanças mais recentes, ocorridas com o surgimento do Fundeb, instituído pela EC n. 53/2006, implicaram alterações profundas, no que diz respeito à estrutura orçamentário-financeira composta pelos entes federados.

Os recursos que compõem o Fundeb são provenientes dos próprios estados e municípios, que destinam, compulsoriamente, $20 \%$ de seus tributos para a educação básica. Além desses recursos, ainda compõe o fundo, a título de complementação, uma parcela de investimento federal, sempre que o valor por aluno, no âmbito do fundo estadual, não alcançar o mínimo definido nacionalmente.

Apesar de o Fundeb não se constituir uma panaceia para os problemas do financiamento da educação básica brasileira, a sua primeira qualidade reside em determinar aos estados e aos respectivos municípios a exercerem a cooperação na oferta do ensino público. Para Fernandes (2009), a EC n. 14/96 já aplainara o caminho da cooperação, estabelecendo as prioridades: os municípios com o encargo da educação infantil, os estados 
Os reflexos no financiamento do sistema estadual de ensino público da Bahia resultantes da nova política de financiamento da educação básica no Brasil

com o ensino médio e ambos dividindo a responsabilidade pelo ensino fundamental, mas o Fundeb,

[...] ao abranger no regime de redistribuição de $20 \%$ dos impostos todas as etapas e modalidades da educação básica, obedecendo a estas prioridades e permitindo a cada ente federativo a aplicação livre da receita recebida, regula com força o princípio da cooperação (FERNANDES, 2009, p. 28).

Com o intuito de evidenciar o princípio de cooperação entre entes federados no financiamento do ensino público como uma das características do Fundeb, apresenta-se a configuração dessa relação entre o governo do Estado da Bahia e os municípios. A seguir, a Tabela 1 mostra a diferença entre o total aportado, ou seja, os valores destinados compulsoriamente ao Fundo pelo governo do Estado da Bahia e o montante recebido, no período de 2009 a 2013, com base no número de alunos de sua rede de ensino e os fatores de ponderação aplicáveis entre diferentes etapas, modalidades e tipos de ensino da educação básica.

Tabela 1 - Diferença entre o total aportado e o montante recebido do Fundeb em moeda corrente - governo do Estado da Bahia - 2009 a 2016 (em R\$ milhões)

\begin{tabular}{c|c|c|c|c|c|c|c|c}
\hline $\begin{array}{c}\text { Especificaçã } \\
\text { o }\end{array}$ & 2009 & 2010 & 2011 & 2012 & 2013 & 2014 & 2015 & 2016 \\
\hline $\begin{array}{c}\text { Aportes pelo } \\
\text { Estado (A) }\end{array}$ & $2.317,8$ & $2.669,8$ & $3.046,7$ & $3.273,5$ & $3.737,3$ & $4.077,8$ & $4.333,6$ & $4.634,0$ \\
\hline $\begin{array}{c}\text { Recebiment } \\
\text { os (B) }\end{array}$ & $1.678,2$ & $1.922,5$ & $2.278,7$ & $2.575,7$ & 2.574 .6 & $2.690,8$ & $2.818,4$ & 2.950 .7 \\
\hline $\begin{array}{c}\text { Diferença } \\
\text { (A-B) }\end{array}$ & 639,6 & 747,3 & 768,0 & 697,8 & $1.162,6$ & $1.387,0$ & $1.515,2$ & $1.683,3$ \\
\hline
\end{tabular}

Fonte: BAHIA/TCE (2010; 2011; 2012; 2013; 2014; 2015; 2016; 2017).

Os dados demonstram um valor crescente de recursos aportados pelo governo do Estado da Bahia ao Fundo estadual, no período de 2009 a 2016. Constata-se também que os valores aportados superam, significativamente, os valores recebidos. A maior diferença entre aportes e recebimentos foi registrada no exercício 2016. As diferenças registradas em cada ano significam que esses recursos retornam para outros entes federados (municípios), no âmbito do estado, conforme os critérios instituídos para esse fundo. Assim, o princípio de cooperação entre o estado e seus municípios, na conjuntura do Fundeb, reside na dinâmica de redistribuição dos recursos de impostos estaduais e municipais no limite de cada estado, pelo critério das matrículas de cada rede de ensino, de acordo com o censo escolar do ano anterior.

Conforme já mencionado, a distribuição de recursos do Fundeb dar-se-á na proporção do número de alunos matriculados nas respectivas redes de educação básica pública presencial, de acordo com o censo escolar do ano anterior. Destarte, o fato de o Governo do Estado da Bahia aportar mais recursos ao Fundo do que o valor que recebe, pode ter relações diretas com o processo de municipalização do ensino, o qual foi intensificado com a implementação do Fundef. Estudos de Costa (2008, p. 92) dão conta de que $40 \%$ das unidades escolares estaduais foram municipalizadas no período de 1998 a 2004, totalizando 426.818 alunos transferidos para os municípios, o equivalente a $31,6 \%$ da totalidade de sua matrícula em 1997, ano anterior ao início da municipalização.

Acrescentando a análise sobre os reflexos do atual modelo de financiamento da educação adotado no Brasil sobre o sistema estadual de ensino da Bahia, considera-se importante ampliar o estudo, levando em conta a complementação recebida pelo Fundeb 
Os reflexos no financiamento do sistema estadual de ensino público da Bahia resultantes da nova política de financiamento da educação básica no Brasil

Bahia que abrange o seu sistema de ensino e os de seus municípios, decorrente da insuficiência de recursos para alcançar o valor mínimo nacional por aluno estabelecido anualmente. O Fundo do Estado da Bahia recebe complementação desde a implantação da política de fundos. O próximo item detém-se nesta análise.

\section{Configuração da complementação da União ao Fundeb Bahia e expectativas para a implementação do CAQi}

No período estudado (2009 a 2016), o Fundeb Bahia, considerando o governo estadual e os governos municipais, figurou-se dentre aqueles fundos estaduais que receberam recursos da complementação da União. Esses recursos são destinados aos fundos estaduais em que a arrecadação não tem sido suficiente para garantir o valor mínimo por aluno, que é estabelecido anualmente na esfera federal. Os recursos oriundos da complementação da União devem ser utilizados pelos entes federativos no exercício financeiro em que lhes forem creditados, em ações consideradas como de manutenção e desenvolvimento do ensino para a educação básica pública, consoante o art. 70 da LDBEN/96, apresentado anteriormente.

A seguir, a Tabela 2 mostra os valores da complementação da União ao Fundeb do Estado da Bahia (receitas efetivas), que abrange o sistema estadual e os municípios.

Tabela 2 - Complementação da União ao Fundo do Estado da Bahia, em moeda corrente 2009 a 2016 (em R\$ milhões)

\begin{tabular}{c|c|c|c|c|c|c|c|c}
\hline $\begin{array}{c}\text { Especifi } \\
\text { Cação }\end{array}$ & 2009 & 2010 & 2011 & 2012 & 2013 & 2014 & 2015 & 2016 \\
\hline $\begin{array}{c}\text { Complem } \\
\text { entação } \\
\text { da União }\end{array}$ & $1.109,9$ & $1.766,7$ & $1.674,7$ & $2.013,1$ & $2.144,1$ & $2.498,5$ & $2.430,7$ & $2.708,8$ \\
\hline
\end{tabular}

Fonte: BRASIL; MEC/FNDE (2010; 2011; 2012; 2013; 2014; 2015; 2016; 2017).

O crescimento mais expressivo da complementação da União ao Fundo da Bahia foi registrado entre os anos de 2009 e 2010. Percebe-se uma tendência de crescimento, ainda que tímida nos valores da complementação, exceto em 2011 e 2015. Como se vê, o montante de recursos anualmente alocados para a complementação do Fundeb da Bahia mostra o grau de dependência que seus municípios possuem em relação a esses repasses. Isso evidencia que, apesar da tendência de ampliação de recursos da complementação, o modelo de financiamento da educação básica, a partir da política de fundos, não tem sido suficiente para atender às necessidades educacionais dos sistemas de ensino.

Partindo de uma análise mais geral, autores fazem ponderações sobre os efeitos dos fundos na resolução dos problemas do financiamento da Educação. Para Davies (2008), o Fundeb está longe de se configurar como solução para os males da educação básica, uma vez que: traz poucos recursos novos; estabelece um padrão de qualidade vago e contraditório; conta com uma complementação federal muito pequena; favorece recursos para instituições privadas, no caso da Educação Especial, creches e pré-escolas comunitárias, confessionais e filantrópicas; e não garante a valorização dos profissionais da educação. Uma das críticas mais contundentes que os autores fazem da política de fundos implantada no Brasil reside no fato de que a distribuição dos recursos se dá dentro de cada estado, não contribuindo para uma distribuição mais equitativa dos recursos, considerando as grandes desigualdades regionais do País em termos de suporte financeiro para custear a educação. Esse cenário torna-se elucidado quando se compara o valor anual por aluno estimado em 2016 - último ano do período estudado - das séries iniciais urbanas do ensino fundamental da Bahia, na 
Os reflexos no financiamento do sistema estadual de ensino público da Bahia resultantes da nova política de financiamento da educação básica no Brasil

região Nordeste e de São Paulo, na região Sudeste. Enquanto na Bahia esse valor foi de $\mathrm{R} \$$ 2.739,87, em São Paulo chegou-se a R\$3.597,37 (BRASIL; MEC/FNDE, 2017).

O último marco em destaque, neste trabalho, referente às mudanças na política de financiamento da educação básica, diz respeito à definição do padrão mínimo de qualidade via patamar de investimento público direto em políticas educacionais como proporção do PIB, disposto no PNE 2014-2024.

Conforme assinalado, a meta 20 do PNE trata da ampliação do investimento público em educação pública de forma a atingir, no mínimo, o patamar de $7 \%$ do PIB do País, no $5^{\circ}$ ano de vigência do Plano e, no mínimo, o equivalente a $10 \%$ do PIB, ao final do decênio. Desse modo, institui-se as condições legais para que o Custo Aluno Qualidade (CAQ) se firme como parâmetro do padrão de qualidade.

Retomando a discussão feita anteriormente sobre o CAQ e o CAQi, destaca-se o entendimento de Pinto (2006) quando afirma que esse segundo indicador é um ponto de partida pois, na medida em que os parâmetros de atendimento melhoram, aumenta-se também o grau de exigência e novas metas de qualidade vão sendo incorporadas. Esse entendimento está expresso no novo PNE.

Com o objetivo de evidenciar os desafios do CAQi para o financiamento da educação básica, apresenta-se, a seguir, a Tabela 3, com a estimativa da complementação da União ao Fundeb Bahia, ano 2016, com base nos cálculos divulgados na Nota Técnica 01/2016, da Campanha Nacional pelo Direito à Educação e da Associação Nacional de Pesquisa e Financiamento da Educação. Esses cálculos foram atualizados a partir do Parecer CEB/CNE n. 8/2010, que trata dos padrões mínimos de qualidade de ensino para a Educação Básica pública.

Tabela 3 - Estimativa da complementação da União ao Fundeb Bahia de modo a viabilizar o CAQi. Ano: 2016 (R\$ em milhões)

\begin{tabular}{c|c|c|c|c}
\hline UF & $\begin{array}{c}\text { Recursos previstos } \\
\text { no âmbito do } \\
\text { Fundeb }\end{array}$ & $\begin{array}{c}\text { Recursos } \\
\text { necessários para } \\
\text { garantir o CAQi }\end{array}$ & $\begin{array}{c}\text { Complemento da } \\
\text { União previsto }\end{array}$ & $\begin{array}{c}\text { Complemento } \\
\text { necessário para o } \\
\text { CAQi }\end{array}$ \\
\hline Bahia & 6.976 & 15.023 & 2.502 & 8.046 \\
\hline \multicolumn{2}{r}{ Fonte: CAMPANHA NACIONAL PELO DIREITO À EDUCAÇÃO; FINEDUCA (2016). }
\end{tabular}

Conforme os dados apresentados na Tabela 3, observa-se que os valores previstos a serem aportados pelo Estado da Bahia e seus municípios, no ano 2016, distanciam-se demasiadamente dos recursos necessários para garantir o CAQi. Soma-se a isso o fato de que a previsão de complementação da União para o Fundo Estadual da Bahia nesse mesmo ano foi de 2,5 bilhões, enquanto que no cenário do CAQi seria necessária uma complementação acima de 8 bilhões. Portanto, a viabilização do CAQi, a partir do Fundeb Bahia para concretizar o padrão mínimo de qualidade, depende de maior complementação da União.

\section{Considerações Finais}

As mudanças ocorridas na política de financiamento da educação básica brasileira pós $\mathrm{CF} / 88$ evidenciam a distinção da educação dentre as diferentes políticas públicas, tornandose "[...] a expressão legal da prioridade estratégica que se atribui à educação, quando se pensa num projeto de desenvolvimento econômico e de construção da cidadania" (OLIVEIRA, 1998 , p. 125-126). Conforme ilustrado neste artigo, as mudanças produziram reflexos 
Os reflexos no financiamento do sistema estadual de ensino público da Bahia resultantes da nova política de financiamento da educação básica no Brasil

significativos e peculiares no financiamento do sistema de ensino do Estado da Bahia. Ao mesmo tempo, observa-se que os investimentos públicos em educação, na esfera do governo estadual, considerando a série de anos avaliada neste estudo, não conseguem suprir as necessidades financeiras de forma a considerar, na política educacional, o conceito do CAQi, como preconiza o Plano Nacional de Educação, Lei 13.005/2014. A reflexão sobre essa situação produz preocupação a educadores, pesquisadores e interessados pelas políticas públicas, quando não se vislumbra as possibilidades de fazer valer os preceitos sobre o direito à educação da população.

A vinculação de percentuais mínimos de receitas provenientes de impostos à manutenção e desenvolvimento do ensino, advinda da CF/88, se apresenta como um instrumento para a garantia do direito à educação. Apesar de o Estado da Bahia, no período pesquisado (2009-2016), atender ao disposto na legislação em relação a esse aspecto, houve um decréscimo linear nos três primeiros anos $(2009,2010$ e 2011) e um acréscimo considerável no período entre 2013 e 2015, que superou os percentuais de todo o período, tendendo a diminuir em 2016. Esse achado sugere a necessidade de estudos mais específicos e aprofundados com o intuito de uma maior compreensão sobre o fenômeno, conforme já pontuado neste trabalho.

Outra constatação referente às mudanças na política de financiamento da educação básica, em especial aos efeitos causados pelo Fundeb, diz respeito à superação dos valores aportados pelo governo do Estado da Bahia, ao Fundo de âmbito estadual, em relação aos valores recebidos, conforme o período analisado. Isso fortalece a tese de que o Fundeb se constitui instrumento de cooperação entre os entes federados, na oferta do ensino público (FERNANDES, 2009). No entanto, observa-se o limite dessa cooperação, já que a distribuição dos recursos do Fundo se dá dentro de cada Estado, não contribuindo para uma distribuição mais equitativa dos recursos, considerando as grandes desigualdades regionais do País em termos de suporte financeiro para custear a educação.

Por fim, a definição do padrão mínimo de qualidade, via patamar de investimento público direto em políticas educacionais como proporção do PIB, explicitado no PNE 2014-2024, vislumbra alternativas oportunas para enfrentar os problemas históricos, no financiamento da educação brasileira. Apesar disso, permanecem indefinidas as fontes de onde virão os recursos adicionais. No caso da Bahia, em 2016, seria necessária uma complementação significativa da União ao Fundeb para garantir o padrão mínimo de qualidade, via CAQi (CAMPANHA NACIONAL PELO DIREITO À EDUCAÇÃO; FINEDUCA, 2016).

Apesar de alguns avanços e conquistas, o financiamento da educação básica brasileira, em sua atual configuração, está permeado de incertezas e desafios. Diante disso, a concretização do investimento público em educação, conforme padrões mínimos de qualidade para superação das desigualdades regionais e o alcance de uma educação de melhor qualidade como direito de todos, pode ser considerada uma incógnita.

\section{Referências}

BAHIA. Tribunal de Contas do Estado. Relatório e Parecer Prévio das Contas do Estado da Bahia: Poder Executivo exercício de 2009. Salvador: TCE/BA, 2010.

BAHIA. Tribunal de Contas do Estado. Relatório e Parecer Prévio das Contas do Poder

Executivo do Estado da Bahia: exercício de 2010. Salvador: TCE/BA, 2011. 
Os reflexos no financiamento do sistema estadual de ensino público da Bahia resultantes da nova política de financiamento da educação básica no Brasil

BAHIA. Tribunal de Contas do Estado. Relatório e Parecer Prévio das Contas do Poder Executivo do Estado da Bahia: exercício de 2011. Salvador: TCE/BA, 2012.

BAHIA. Tribunal de Contas do Estado. Relatório e Parecer Prévio do TCE sobre as Contas do Estado da Bahia: Poder Executivo exercício de 2012. Salvador: TCE/BA, 2013.

BAHIA. Tribunal de Contas do Estado. Relatório e Parecer Prévio do TCE sobre as Contas do Poder Executivo do Estado da Bahia: exercício de 2013. Salvador: TCE/BA, 2014.

BAHIA. Tribunal de Contas do Estado. Relatório e Parecer Prévio do TCE sobre as Contas do Poder executivo do Estado da Bahia. Exercício 2014. Salvador: TCE/BA, 2015.

BAHIA. Tribunal de Contas do Estado. Relatório e Parecer Prévio do TCE sobre as Contas do Poder executivo. Exercício 2015. Salvador: TCE/BA, 2016.

BAHIA. Tribunal de Contas do Estado. Relatório e Parecer Prévio do TCE sobre as Contas do Poder executivo. Exercício 2016. Salvador: TCE/BA, 2017.

BOBBIO, Norberto. A Era dos Direitos. Rio de Janeiro: Campus, 1992.

BRASIL. Conselho Nacional de Educação. Parecer CNE/CEB № 8/2010. Estabelece normas para aplicação do inciso IX do artigo 4o da Lei no 9.394/96 (LDB), que trata dos padrões mínimos de qualidade de ensino para a Educação Básica. Disponível em: <http://www.mec.gov.br/cne>. Acesso em: 15 mar. 2018.

BRASIL. Constituição da República Federativa do Brasil. Diário Oficial da União, Brasília, DF, 1988. Disponível em: <http://www.planalto.gov.br/ccivil_03/constituicao/constitui\% C3\%A7ao.htm>. Acesso em: 12 maio 2017.

BRASIL. Lei de Diretrizes e Base da Educação Nacional 9.394/96. Diário Oficial da União, Brasília, DF, 1996. Disponível em: <http://www.planalto.gov.br/ccivil_03/LEIS//9394.htm>. Acesso em: 15 maio 2017.

BRASIL. Emenda Constitucional n 14, de 12 de setembro de 1996. Diário Oficial da União, Brasília, 13 set. 1996.

BRASIL. Emenda Constitucional $n^{\circ} 53$, de 19 de dezembro de 2006. Diário Oficial da União, Brasília, 20 dez. 2006.

BRASIL. Emenda Constitucional $n^{\circ} 59$, de 11 de novembro de 2009. Diário Oficial da União, Brasília, 12 nov. 2009.

BRASIL. Lei $n^{\circ}$ 12.858, de 9 de setembro de 2013. Diário Oficial da União, Brasília, DF, 2013. Disponível em: <http://www.planalto.gov.br/ccivil_03/_Ato2011-2014/2012/Lei/L127 44.htm>. Acesso em: 10 mar. 2018.

BRASIL. Lei no 13.005 de 25 de junho de 2014. Diário Oficial da União, Brasília, DF, 2014. Disponível em: <http://pesquisa.in.gov.br/imprensa/jsp/visualiza/index.jsp?data=26\%2F06\% 2F2014\&jornal=1000\&pagina=1\&totalArquivos=8>. Acesso em: 20 maio 2017.

BRASIL. MEC/FNDE. Portaria MEC n 496, de 16 de abril de 2010. Brasília, 2010. Disponível em: $\quad<$ http://www.fnde.gov.br/financiamento/fundeb/sobre-o-plano-ou-programa/legislacaofundeb?start=50>. Acesso em: 07 maio 2018. 
Os reflexos no financiamento do sistema estadual de ensino público da Bahia resultantes da nova política de financiamento da educação básica no Brasil

BRASIL. MEC/FNDE. Portaria MEC n³80, de 06 de abril de 2011. Brasília, 2011. Disponível em: $\quad<$ http://www.fnde.gov.br/financiamento/fundeb/sobre-o-plano-ou-programa/legislacaofundeb?start=50>. Acesso em: 07 maio 2018.

BRASIL. MEC/FNDE. Portaria MEC n 437, de 20 de abril de 2012. Brasília, 2012. Disponível em: $\quad<$ http://www.fnde.gov.br/financiamento/fundeb/sobre-o-plano-ou-programa/legislacaofundeb?start=40>. Acesso em: 07 maio 2018.

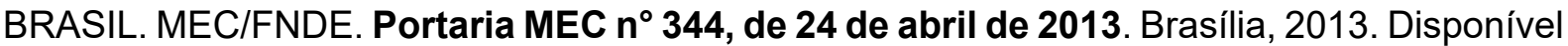
em: $\quad<$ http://www.fnde.gov.br/financiamento/fundeb/sobre-o-plano-ou-programa/legislacaofundeb?start=30>. Acesso em: 10 maio 2018.

BRASIL. MEC/FNDE. Portaria MEC n 364, de 28 de abril de 2014. Brasília, 2014. Disponível em: <http://www.fnde.gov.br/financiamento/fundeb/sobre-o-plano-ou-programa/legislacaofundeb?start=30>. Acesso em: 10 maio 2018.

BRASIL. MEC/FNDE. Portaria $\mathbf{n}^{\circ}$ 317, de 27 de março de 2015. Brasília, 2015. Disponível em: <http://www.fnde.gov.br/financiamento/fundeb/sobre-o-plano-ou-programa/legislacaofundeb?start=20>. Acesso: em 10 maio 2018.

BRASIL. MEC/FNDE. Portaria MEC $\mathbf{n}^{\circ}$ 229, de 8 de abril de 2016. Brasília, 2016. Disponível em: <http://www.fnde.gov.br/financiamento/fundeb/sobre-o-plano-ou-programa/legislacaofundeb?start=10>. Acesso em: 28 maio 2018.

BRASIL. MEC/FNDE. Portaria MEC No 565, de 20 de abril de 2017. Brasília, 2017. Disponível em: <http://www.fnde.gov.br/financiamento/fundeb/sobre-o-plano-ou-programa/ legislacao-fundeb?start=10>. Acesso em: 28 maio 2018.

CAMPANHA NACIONAL PELO DIREITO À EDUCAÇÃO; FINEDUCA. Nota 1/2016 - A aprovação da PEC 241 significa estrangular a educação pública brasileira e tornar letra morta o Plano Nacional de Educação 2014-2024. Disponível em: <http://campanha.org.br/wpcontent/uploads/2016/10/NotaFINEDUCA_01_2016_final.pdf>. Acesso em: 08 jul. 2018.

CARA, Daniel. Por Que $10 \%$ do PIB Para a Educação Pública? A Posição da Campanha Nacional pelo Direito à Educação. Educação em Revista, Marília, v. 13, n. 1, p. 13-30, jan./jun. 2012.

COSTA, Jean Mário Araújo. A municipalização do ensino via cooperação entre entes federados: um estudo em dois municípios do território do sisal no semiárido baiano. 2008. Dissertação (Mestrado) - Universidade Federal da Bahia, Salvador, 2008.

CURY, Carlos Roberto Jamil. Direito à educação: direito à igualdade, direito à diferença. Cadernos de Pesquisa, São Paulo, n. 116, p. 245-262, 2002.

DAVIES, Nicholas. FUNDEB: a redenção da educação básica? Campinas: Autores Associados, 2008.

FERNANDES, Francisco das Chagas. O Fundeb como política pública de financiamento da educação básica. Revista Retratos da Escola, Brasília, v. 3, n. 4, p. 23-38, jan./jun. 2009. 
Os reflexos no financiamento do sistema estadual de ensino público da Bahia resultantes da nova política de financiamento da educação básica no Brasil

GEMAQUE, Rosana M. O Financiamento da Educação. O Fundef no Estado do Pará: Feitos e Fetiches. 2004. 370 f. Tese (Doutorado) - Faculdade de Educação, Universidade de São Paulo, São Paulo, 2004.

GOUVEIA, Andréia Barbosa; SOUZA, Ângelo Ricardo. A política de fundos em perspectiva histórica: mudanças de concepção da política na transição Fundef e Fundeb. Em Aberto, Brasília, v. 28, n. 93, Brasília, 2015.

JESUS, Wellington Ferreira de. Do Valor/Aluno/Ano ao Custo-Aluno-Qualidade-Inicial: o controle social na consolidação dos fundos constitucionais como política de estado. Revista da FAEEBA - Educação e Contemporaneidade, Salvador, n. 38, v. 21, p. 215-225, jul./dez. 2012.

MARTINS, Paulo de Sena. O financiamento da educação básica como política pública. Revista Brasileira de Política e Administração da Educação, Porto Alegre, v. 26, n. 3, set./dez. 2010.

OLIVEIRA, Romualdo Portela de. O financiamento público da educação e seus problemas. In: OLIVEIRA, Romualdo Portela de (Org.). Política Educacional: impasses e alternativas. São Paulo: Cortez, 1998. P. 124-144.

PINTO, José Marcelino R. Uma proposta de custo-aluno-qualidade na educação básica. Revista Brasileira de Política e Administração da Educação, Goiânia, v. 22, p. 197-227, 2006.

PINTO, José Marcelino R. A política recente de fundos para o financiamento da educação e seus efeitos no pacto federativo. Educação e Sociedade, Campinas, v. 28, n. 100, p. 877897, 2007.

SILVA, Carlos Daniel; JESUS, Wellington Ferreira de. O desafio do financiamento da educação nos estados e a meta 20 do PNE (2014-2024). In: CONGRESSO IBEROAMERICANO DE POLÍTICA E ADMINISTRAÇÃO DA EDUCAÇÃO, 5.; CONGRESSO LUSOBRASILEIRO DE POLÍTICA E ADMINISTRAÇÃO DA EDUCAÇÃO, 8., 2016, Goiânia. Anais... Goiânia: Biblioteca ANPAE; Série Cadernos ANPAE, v. 41, Goiânia, 2016.

VIEIRA, Sofia Lerche; VIDAL, Eloisa Maia. Política de financiamento da educação no Brasil: uma (re)construção histórica. Em Aberto, Brasília, v. 28, n, 93, Brasília, 2015.

Jean Mário Araújo Costa é doutor em Educação pela Universidade Federal da Bahia (UFBA), Mestre em Educação pela UFBA, graduado em Pedagogia pela Universidade do Estado da Bahia (UNEB), Especialista em Política do Planejamento Pedagógico: currículo, didática e avaliação pela UNEB. Integra a Linha de Pesquisa Políticas e Gestão da Educação do Programa de Pesquisa e Pós-Graduação em Educação da UFBA. É pesquisador do Grupo de Pesquisa Gestão e Avaliação de Políticas e Projetos Sociais (GAPPS), da Universidade Católica do Salvador (UCSal).

E-mail: jeanmario.pce@gmail.com 
Os reflexos no financiamento do sistema estadual de ensino público da Bahia resultantes da nova política de financiamento da educação básica no Brasil

Maria Couto Cunha possui graduação em Licenciatura em Ciências Sociais pela Universidade Federal da Bahia (1972), graduação em Bacharelado em Ciências Sociais pela Universidade Federal da Bahia (1973), mestrado em Educação pela Universidade Federal da Bahia (1978) e doutorado em Educação pela Universidade Federal da Bahia (2002). É professora no Programa de Pós-Graduação em Educação da Faculdade de Educação da Universidade Federal da Bahia, com experiência na área de Educação, com ênfase em Política e Gestão da Educação.

E-mail: mariacoutocunha@gmail.com

Cláudia Sá Malbouisson Andrade possui Graduação em Economia pela Universidade Federal da Bahia (2001), Mestrado em Economia pela Universidade Federal da Bahia (2004) e Doutorado em Economia pela Universidade Federal de Pernambuco (2009). Atualmente, é Professora Adjunta do Departamento de Economia e PPGE da Universidade Federal da Bahia e pesquisadora do Grupo de Pesquisas em Economia Aplicada.

E-mail: cmalbo@ufba.br 


\title{
Editores do volume 8
}

José Marcelino de Rezende Pinto - Universidade de São Paulo, São Paulo/SP, Brasil

Nalú Farenzena - Universidade Federal do Rio Grande do Sul, Porto Alegre/RS, Brasil

\section{Comitê Editorial}

José Marcelino de Rezende Pinto - Universidade de São Paulo, Brasil

Juca Gil - Universidade Federal do Rio Grande do Sul, Brasil

Theresa Adrião - Universidade Estadual de Campinas, Brasil Ângelo

Ricardo de Souza - Universidade Federal do Paraná, Brasil

Márcia Aparecida Jacomini - Universidade Federal de São Paulo, Brasil

\section{Conselho Editorial}

\section{Alejandro Morduchowicz}

Universidad Pedagógica, Provincia de Buenos Aires, Argentina

Fernanda Saforcada

Universidade de Buenos Aires, Argentina

Jacques Velloso

Universidade de Brasília, Brasil

João Monlevade

Senado Federal, Brasil

Jorge Abrahão de Castro

Instituto de Pesquisa Econômica Aplicada / IPEA, Brasil

Juca Gil

Universidade Federal do Rio Grande do Sul, Brasil

Lisete Regina Gomes Arelaro

Universidade de São Paulo, Brasil

Luis Carlos Sales

Universidade Federal do Piauí, Brasil

Luiz de Sousa Junior

Universidade Federal da Paraíba, Brasil

Luiz Fernandes Dourado

Universidade Federal de Goiás, Brasil

Magna França

Universidade Federal do Rio Grande do Norte, Brasil

\section{Maria Beatriz Luce}

Universidade Federal do Pampa, Brasil

Universidade Federal do Rio Grande do Sul, Brasil

Marcos Edgar Bassi

Universidade Federal do Paraná, Brasil

\author{
Maria Dilnéia Espíndola Fernandes \\ Universidade Federal de Mato Grosso do Sul, Brasil \\ Nalú Farenzena \\ Universidade Federal do Rio Grande do Sul, Brasil \\ Nelson Cardoso do Amaral \\ Universidade Federal de Goiás, Brasil \\ Nicholas Davies \\ Universidade Federal Fluminense, Brasil \\ Rosana Evangelista Cruz \\ Universidade Federal do Piauí, Brasil \\ Rosana Gemaque \\ Universidade Federal do Pará, Brasil \\ Robert E. Verhine \\ Universidade Federal da Bahia, Brasil \\ Romualdo Portela de Oliveira \\ Universidade de São Paulo, Brasil \\ Theresa Adrião \\ Universidade Estadual de Campinas, Brasil \\ Tristan McCowan \\ University of London, Reino Unido \\ Vera Jacob \\ Universidade Federal do Pará, Brasil \\ Vera Peroni \\ Universidade Federal do Rio Grande do Sul, Brasil \\ Vitor Henrique Paro \\ Universidade de São Paulo, Brasil
}

\section{Equipe editorial}

Apoio ao Comitê Editorial: Patrícia Balthazar Garcia

Diagramação, Revisão de português e normalização: Edson Leonel de Oliveira

Revisão de inglês: Ananyr Porto Fajardo 